OPEN ACCESS

Edited by:

Lixing Yuan,

China Agricultural University, China

Reviewed by:

Nina Nikolic,

University of Belgrade, Serbia

Zhenhua Zhang,

Hunan Agricultural University, China

*Correspondence:

Yongchao Liang

ycliang@zju.edu.cn

Specialty section:

This article was submitted to

Plant Nutrition,

a section of the journal

Frontiers in Plant Science

Received: 02 January 2020

Accepted: 19 February 2020

Published: 12 March 2020

Citation:

Yan G, Fan X, Peng M, Yin C,

Xiao Z and Liang Y (2020) Silicon Improves Rice Salinity Resistance by Alleviating lonic Toxicity and Osmotic

Constraint in an Organ-Specific

Pattern. Front. Plant Sci. 11:260.

doi: 10.3389/fpls.2020.00260

\section{Silicon Improves Rice Salinity Resistance by Alleviating lonic Toxicity and Osmotic Constraint in an Organ-Specific Pattern}

\author{
Guochao Yan, Xiaoping Fan, Miao Peng, Chang Yin, Zhuoxi Xiao and Yongchao Liang* \\ Ministry of Education Key Laboratory of Environment Remediation and Ecological Health, College of Environmental \\ and Resource Sciences, Zhejiang University, Hangzhou, China
}

Salinity stress severely inhibits the growth of plant via ionic toxicity and osmotic constraint. Exogenous silicon (Si) can alleviate salinity stress, but the mechanisms behind remain unclear. To investigate the role of $\mathrm{Si}$ in alleviating ionic and osmotic components of salinity, rice (Oryza sativa L.) seedlings were grown hydroponically in iso-osmotic stress conditions developed from $\mathrm{NaCl}$ or polyethylene glycol (PEG). The effects of Si on the growth of shoot and root of rice under salinity and PEG-derived osmotic stress were evaluated and further compared using principal coordinate analysis (PCOA). We also analyzed the concentrations of $\mathrm{Na}, \mathrm{K}$, and compatible osmolytes, tissue sap osmotic potential, antioxidant enzymes activities, and the expression of aquaporin genes. Generally, Si significantly promoted shoot and root growth in rice exposed to both $\mathrm{NaCl}$ and PEG. PCoA shows that the Si-induced distance change under $\mathrm{NaCl}$ treatment was larger than that under PEG treatment in the shoot, while the Si-induced distance changes under $\mathrm{NaCl}$ and $\mathrm{PEG}$ treatments were at an equal level in the root. Under salinity, Si decreased $\mathrm{Na}$ concentration and $\mathrm{Na} / \mathrm{K}$ ratio in the shoot but not in the root. However, Si decreased net Na uptake and increased root $\mathrm{Na}$ accumulation content. Osmotic potential was increased in the shoot but decreased in the root by $\mathrm{Si}$ addition. Si decreased soluble sugar and proline concentrations in the shoot but increased soluble sugar and soluble protein concentrations in the root. Besides, Si promoted shoot transpiration rate and root morphological traits. Although both $\mathrm{NaCl}$ and $\mathrm{PEG}$ treatments upregulated aquaporin gene expression, Si addition maintained the expression of OsPIPs under $\mathrm{NaCl}$ and PEG treatments at same levels as control treatment. Furthermore, Si alleviated oxidative damages under both $\mathrm{NaCl}$ and PEG by regulating antioxidant enzyme activities. In summary, our results show that $\mathrm{Si}$ improves salt stress tolerance in rice by alleviating ionic toxicity and osmotic constraint in an organ-specific pattern. Si ameliorates ionic toxicity by decreasing $\mathrm{Na}$ uptake and increasing root Na reservation. Si alleviates osmotic constraint by regulating root morphological traits and root osmotic potential but not aquaporin gene expression for water uptake, and promoting transpiration force but not osmotic force in shoot for root-to-shoot water transport.

Keywords: silicon, salinity, rice (Oryza sativa L.), osmotic constraint, ionic toxicity 


\section{INTRODUCTION}

Silicon (Si) is the second most abundant element in soil and a widely recognized beneficial element in plant (Epstein, 1994, 1999; Liang et al., 2015). The alleviation effect of Si on salinity stress, one of the major environmental problems, has been found in different kinds of plant species including rice, barley, wheat, sorghum, tomato, and cucumber (Liang et al., 2003; Zhu et al., 2004; Gong et al., 2006; Hattori et al., 2007; Saqib et al., 2008; Shi et al., 2016). Salinity stress limits crop production severely and causes inestimable economic loss globally. The situation is getting worse due to global warming and excess chemical fertilization (Munns and Gilliham, 2015). Under such a background, the application of Si fertilizer would be a promising approach with the advantages of high efficiency and low economic cost (Liang et al., 2015; Yan et al., 2018). However, the veiled mechanism behind Siinduced salt stress tolerance impedes the extensive application of Si fertilizer in agriculture.

When grown under salinity stress, plants suffer from two stress components: osmotic constraint and ionic toxicity (Munns and Tester, 2008). Excess salt ions (mainly $\mathrm{Na}$ ) in growth substance would cause osmotic potential decline, which limits root water uptake and induces successive tissue dehydration (Munns, 2002). The accumulation of salt ions in plant tissues, especially in photosynthetic organ, would increase inevitably over time and successively disrupt plant $\mathrm{Na} / \mathrm{K}$ balance and essential metabolism (Zhu, 2001; Kronzucker and Britto, 2011; Wakeel et al., 2011). In addition, both ionic and osmotic components of salinity can induce reactive oxygen species accumulation and membrane peroxidation (Munns, 2002; Munns and Tester, 2008). In rice, Si has been found to play a role as physical barrier in the root and block $\mathrm{Na}$ apoplastic transport pathway (Gong et al., 2006). Si addition can also improve water use efficiency in rice seedlings under salt stress (Shi et al., 2013). In sorghum, Si can decrease shoot $\mathrm{Na}$ concentration by regulating polyamine metabolism (Yin et al., 2016) and enhance root water hydraulic conductance and plant water uptake when grown under salinity (Liu et al., 2015). Si was also found to promote the ability of $\mathrm{Na}$ compartmentation and the nutrient status in barley under salt stress (Liang et al., 2005b). In cucumber grown under saline condition, Si protects plant from salinity-induced water deficit and ionic toxicity by decreasing $\mathrm{Na}$ uptake, regulating compatible solutes metabolism, and improving root water uptake (Wang et al., 2015; Zhu et al., 2015, 2016). Altogether, Si can improve plant salt tolerance by alleviating both ionic toxicity and osmotic constraint at the same time. Therefore, a better understanding of the contribution of Si-induced ionic and osmotic tolerance improvement to plant growth under salt stress and the expatiating on the associated mechanisms would be key issues to get the whole picture of the beneficial roles of Si under salinity.

Iso-osmotic growth conditions would be an effective method to discriminate the relative contribution of Siinduced ionic detoxification and osmotic stress alleviation to elucidate the underlying mechanisms. Upon dissecting the outcomes of researches aiming to distinguish the ionic effect from osmotic components on plant growth without Si addition, we know that a comparison between the effects of salinity and iso-osmotic conditions developed from nonpenetrant chemicals (e.g., polyethylene glycol, PEG) would be suitable. The ionic effect of salinity can be isolated by subtracting the osmotic effect from the total effects of salinity (Lefevre et al., 2001; Munns, 2002). In addition, such comparison has been successfully conducted in rice, wheat, and soybean to distinguish the plant adaptations to ionic and osmotic components of salinity with respect to seed germination, plant growth, proline concentration, polyamine metabolism, K homeostasis, and gene expression (Shabala, 2000; Almansouri et al., 2001; Lefevre et al., 2001; Umezawa et al., 2002; Ahmad et al., 2007).

Rice is one of the most salt-sensitive cereals and a major crop accounting for more food supply than any other crop. Besides, rice is a typical Si accumulator in which the Si transport system has been well-investigated. Thus, rice can benefit from $\mathrm{Si}$ addition at a relatively high level (Ma and Yamaji, 2015; Yan et al., 2018). In this work, rice seedlings were grown under iso-osmotic stress conditions developed from $\mathrm{NaCl}$ or PEG with or without $\mathrm{Si}$ addition to (i) distinguish the growth promotion effects of Si in response to salinity-induced osmotic constraint and ionic toxicity in the shoot and root and (ii) investigate the mechanisms behind Si-induced salinity stress alleviation.

\section{MATERIALS AND METHODS}

\section{Plant Growth and Treatment Application}

Rice (Oryza sativa L. cv. Zhonghua11, ZH11) seeds were sterilized with $10 \%(v / v) \mathrm{H}_{2} \mathrm{O}_{2}$ and then washed five times with deionized water. Seeds of rice were germinated on moist filter paper and then sown on sterilized quartz sand. After 5 days of growth, each 10 rice seedlings were transplanted to a plastic container filled with $3 \mathrm{~L}$ half-strength Kimura nutrient solution prepared as described by Liang et al. (2006), and the nutrient solution was renewed every 3 days. The experiment was conducted in a controlled-environment growth chamber with the temperature regime of $25 \pm 5^{\circ} \mathrm{C}$, humidity regime of $50 \pm 5 \%$ and $14 / 10 \mathrm{~h}$ light/dark period.

Uniform rice seedlings (28 days old) were used for treatment application. $\mathrm{NaCl}$ and PEG (average molecular weight, 6,000) were added with the final concentrations of $100 \mathrm{mM}$ and $18 \%$ $(w / v)$, respectively. For a better discrimination of the effects of $\mathrm{Si}$ in response to ionic and osmotic components of salt stress, $100 \mathrm{mM} \mathrm{NaCl}$ was used in this study (Lefevre et al., 2001). The osmotic potential of nutrient solution was measured with a dew point osmometer (5600, Wescor, United States). $\mathrm{NaCl}$ and PEG addition caused osmotic potential decline of -0.472 and $-0.481 \mathrm{MPa}$, respectively. Si was added in the form of silicic acid, and the final concentration of $\mathrm{Si}$ was $1.5 \mathrm{mM}$. Silicic acid was prepared by passing sodium silicate solution through $\mathrm{H}^{+}$-form cation exchange resin (Amberlite IR120, Sigma, United States) according to Liang et al. (2005a). After a 5-day treatment, rice seedlings were harvested with root and shoot separated. 


\section{Plant Dry Weight and Root Morphological Traits}

Dry weight (DW) was determined after oven drying at $105^{\circ} \mathrm{C}$ for $1 \mathrm{~h}$ and at $80^{\circ} \mathrm{C}$ for $72 \mathrm{~h}$. For root morphological traits analysis, fresh root samples were spread in a water layer immediately and scanned with a root scanner (GXY-A, Top Instrument, China). Total root surface area, total root length, and root number (diameter $>0.5 \mathrm{~mm}$ ) were analyzed using the software compatible to the root scanner.

\section{Chlorophyll Concentration, Photosynthesis Rate, and Transpiration Rate}

Chlorophyll was extracted with $95 \%(v / v)$ ethanol and measured at 665,649 , and $470 \mathrm{~nm}$ using an ultraviolet-visible (UVvis) spectrophotometer (Evolution 201, Thermo Fisher, United States). Chlorophyll concentration was calculated with the formula described by Porra et al. (1989). The second youngest fully expanded leaf was used for photosynthesis rate $(P n)$ and transpiration rate $(T r)$ measurement with a portable photosynthesis system (6400, Licor, United States). $P n$ and $\operatorname{Tr}$ were calculated according to the leaf surface area in the test chamber.

\section{Relative Water Content}

Relative water content (RWC) was measured following the procedure described by Weatherley (1950). Briefly, fresh weight (FW) of each sample was measured immediately after harvest. Then, the samples were incubated in tubes containing $10 \mathrm{ml}$ water on a shaker at $30^{\circ} \mathrm{C}$ for $6 \mathrm{~h}$. After the measurement of turgid weight (TW), samples were dried at $70^{\circ} \mathrm{C}$ for $72 \mathrm{~h}$, and then dry weight (DW) was determined. RWC was calculated as (FW - DW)/(TW - DW).

\section{$\mathrm{Na}$ and $\mathrm{K}$ Concentrations}

Dry shoot and root samples were ground into fine powder and digested in $5 \mathrm{ml} \mathrm{HNO}_{3}$ and $1 \mathrm{ml} \mathrm{H}_{2} \mathrm{O}_{2}$ with a microwave digest system (Jupiter, Sineo, China). The concentrations of $\mathrm{Na}$ and $\mathrm{K}$ were measured with a flame photometer (FP640, Inesa Instrument, China).

\section{Oxidative Damages}

For malondialdehyde (MDA) concentration measurement, rice samples were homogenized with $0.1 \%(w / v)$ trichloroacetic acid solution. After centrifugation at $10,000 \mathrm{rpm}$ for $10 \mathrm{~min}$, the supernatant was mixed with $0.5 \%(w / v)$ thiobarbituric acid solution and incubated at $96^{\circ} \mathrm{C}$ for $20 \mathrm{~min}$. Then, the reaction tubes were centrifuged at $10,000 \mathrm{rpm}$ for $10 \mathrm{~min}$. The absorbance of the supernatant was measured at 600,532 , and $450 \mathrm{~nm}$. The concentration of MDA was calculated according to Heath and Packer (1968).

Electrolyte leakage (EL) was measured with an electrical conductivity meter (FE38, Mettler Toledo, Switzerland) according to Lutts et al. (1996). Briefly, rice samples were washed with deionized water three times and cut into $2-\mathrm{cm}$ pieces. Then, the samples were placed in tubes containing
$10 \mathrm{ml}$ water and incubated on a shaker at $30^{\circ} \mathrm{C}$ for $6 \mathrm{~h}$. After incubation, electrical conductivity was measured as EC1. The tubes were further incubated in boiling water for $30 \mathrm{~min}$, and the electrical conductivity was measured as EC2. EL was calculated as EC1/EC2.

\section{Antioxidant Enzymes Activities}

Fresh root and leaf samples were homogenized with $3 \mathrm{ml}$ sodium phosphate buffer $(50 \mathrm{mM}, \mathrm{pH}=7.8)$ containing $1 \mathrm{mM}$ ethyl diamine tetraacetic acid and $2 \%(w / v)$ polyvinyl pyrrolidone. The raw extract was centrifuged at $4^{\circ} \mathrm{C}$ for $20 \mathrm{~min}$ at $10,000 \mathrm{rpm}$, and the supernatant was used for the measurements of soluble protein concentration and antioxidant enzyme activity. Superoxide dismutase (SOD) activity was determined following the protocol of Giannopolitis and Ries (1977), and 1 U was defined as $50 \%$ inhibition of nitro blue tetrazolium reduction. Ascorbate peroxidase (APX) activity was determined using the procedure described by Nakano and Asada (1981). Catalase (CAT) activity was measured according to Cakmak and Marschner (1992). Polyphenoloxidase (POD) activity assay was conducted with the method described by Liang et al. (2003).

\section{Tissue Sap Osmotic Potential and Osmolytes Concentrations}

Fresh samples were placed into $0.5-\mathrm{ml}$ tubes and frozen in liquid nitrogen for $30 \mathrm{~min}$. Then, the tubes were drilled at the bottom and put into $1.5-\mathrm{ml}$ tubes without lid until plant samples thawed. Tissue sap was collected through centrifugation at 3,000 rpm for $10 \mathrm{~min}$, and $10 \mu \mathrm{l}$ tissue sap was used to measure osmotic potential with a dew point osmolarity meter.

The concentrations of osmolytes including proline, soluble sugar, and soluble protein were analyzed. Soluble protein was measured spectrophotometrically at $595 \mathrm{~nm}$ using the method described by Bradford (1976) with Coomassie brilliant blue G250 and calculated with a standard curve of bovine serum albumin. Proline concentration was assayed according to Bates et al. (1973). Fresh samples were homogenized with $3 \%(w / v)$ aqueous sulfosalicylic acid and incubated in boiling water for $10 \mathrm{~min}$. Then, $1 \mathrm{ml}$ extract was mixed with $1 \mathrm{ml}$ glacial acetic acid and $1 \mathrm{ml}$ ninhydrin solution. The mixture was incubated at $100^{\circ} \mathrm{C}$ for $1 \mathrm{~h}$ and cooled to room temperature; then, $5 \mathrm{ml}$ toluene was added and mixed thoroughly. The absorbance of the upper phase was measured at $520 \mathrm{~nm}$, and proline concentration was calculated with a standard curve. Soluble sugar was extracted from the powder of dry sample three times with $3 \mathrm{ml} 80 \%$ $(v / v)$ ethanol at $80^{\circ} \mathrm{C}$, and the supernatant was collected after centrifugation at 10,000 rpm for $10 \mathrm{~min}$ each time. The extracts were mixed, and the total volume was adjusted to $10 \mathrm{ml}$. Soluble sugar concentration was measured with the anthrone-sulfuric acid method and calculated with a sucrose standard curve.

\section{Aquaporin Gene Expression}

For aquaporin gene expression analysis, rice seedlings were pretreated with or without $1.5 \mathrm{mM}$ silicic acid for 3 days before $\mathrm{NaCl}$ or PEG was added. After 6 or $24 \mathrm{~h}$ of treatment, rice root samples were harvested and saved in liquid nitrogen. 
Total RNA was extracted using a plant RNA extraction kit (MiniBEST, Takara, Japan) and treated with DNase I in the kit to remove genomic DNA. The isolated RNA was then converted to complementary DNA (cDNA) using a prime script RT reagent kit (Takara, Japan). The expression of aquaporin genes (including OsPIP1;1, OsPIP1;2, OsPIP2;1, OsPIP2;2, OsPIP2;4, and OsPIP2;6) was determined by real-time quantitative PCR using TB Green premix Ex Taq (Takara, Japan) on a Lightcycler 480II system (Roche Diagnostics, Switzerland) following manufacturer's instructions. OsActin1 was used as the internal reference. The sequences of primers used in this study are listed in Supplementary Table S1.

\section{Statistical Analysis}

All the data in this research were calculated with Excel (Microsoft, United States) and subjected to two-way analysis of variance (two-way ANOVA). Significant difference was determined with $P<0.05$ [least significant difference (LSD)]. Plant growth data (a composite of DW, Pn, Tr, chlorophyll, MDA, EL, and RWC for the shoot, and a composite of DW, root/shoot ratio, total root length, total root surface area, root number, MDA, EL, and RWC for the root) were converted into a dissimilarity matrix using the Euclidean distances without standardization. For spatial ordinations, principal coordinate analysis (PCoA) was performed using the cmdscale function in "vegan" package of $\mathrm{R}$ (version 3.5.0) (R Core Team, 2014; Oksanen et al., 2019).

\section{RESULTS}

\section{Effects of $\mathrm{NaCl}$ and Iso-Osmotic PEG on Plant Growth}

In rice shoot, $\mathrm{NaCl}$ and PEG decreased DW by 20.12 and $15.02 \%$, respectively. The $\mathrm{MDA}$ concentration and $\mathrm{EL}$ of rice shoot were higher under $\mathrm{NaCl}$ treatment than under PEG treatment. However, there was no significant difference between $\mathrm{NaCl}-$ and PEG-induced decrement of $\mathrm{Pn}$, Tr, chlorophyll concentration, and $\mathrm{RWC}$ in rice shoot (Table 1). In rice root, $\mathrm{NaCl}$ and PEG decreased DW by 43.12 and $22.36 \%$, respectively. In addition, $\mathrm{NaCl}$ treatment caused more severe total length and surface area decline, MDA accumulation, and EL increment in rice root than those under PEG treatment $(P<0.05)$. However, there was no significant difference between root water status decline caused by $\mathrm{NaCl}$ or PEG (Table 2). Together, $\mathrm{NaCl}$ caused more severe growth limitation and damages in rice than $\mathrm{PEG}$.

\section{Effects of Si on Plant Growth Under $\mathrm{NaCl}$ and Iso-Osmotic PEG}

Under control condition, Si addition had no obvious effect on rice seedling growth (Tables 1, 2). However, in rice shoot, $\mathrm{Si}$ addition alleviated the $\mathrm{NaCl}$-induced decline of DW, $\mathrm{Pn}, \mathrm{Tr}$, and chlorophyll concentration (Table 1). Silicon also promoted root growth under salt stress with higher root DW and better root morphological traits (Table 2). In addition, exogenous $\mathrm{Si}$ significantly improved RWC and decreased MDA concentration and EL in both the shoot and root $(P<0.05$, Tables 1, 2). The growth promotion effect of $\mathrm{Si}$ was also observed under PEG treatment but differed significantly from that under $\mathrm{NaCl}$. Si improved shoot DW by 17.58 and $11.24 \%$ and improved root DW by 26.23 and $14.50 \%$ under $\mathrm{NaCl}$ and $\mathrm{PEG}$, respectively. In rice shoot, $\mathrm{Pn}, \mathrm{Tr}$, and chlorophyll concentration were improved by $\mathrm{Si}$ addition by $18.39,23.20$, and $12.53 \%$ under $\mathrm{NaCl}$, and by 14.14 , 15.20, and $15.47 \%$ under PEG, respectively (Table 1). In rice root, Si addition promoted total root length, root surface area, and root number under $\mathrm{NaCl}$ and PEG at similar levels (Table 2). Under both $\mathrm{NaCl}$ and PEG treatments, Si addition decreased MDA concentration and EL significantly $(P<0.05)$ in rice shoot and root, while the alleviation effects on oxidative damages were more significant under $\mathrm{NaCl}$ than those under PEG. Moreover, the promotion effect of $\mathrm{Si}$ on RWC under $\mathrm{NaCl}$ was close to that under PEG in both the shoot and root (Tables 1, 2).

To parse the growth promotion effects of $\mathrm{Si}$ in response to ionic and osmotic components of salt stress comprehensibly, PCoA was conducted to compare the growth parameters of rice root or shoot under different treatments in Tables 1, 2. The results showed that the first principal axis accounts for 92.71 and $89.54 \%$ variation of shoot and root growth parameters, respectively (Figures 1A,B). Box plots were further plotted based on the data mapped on the first axis of PCoA to visualize the effects of stress conditions and Si addition (Figures 1C,D). The distance between $\mathrm{NaCl}$ and control was larger than that between PEG and control in both the shoot and root, and the corresponding distance became smaller when Si was added (Figures 1C,D). However, the Si-induced distance change under $\mathrm{NaCl}$ treatment was larger than that under PEG treatment in rice shoot, while the Si-induced distance changes under $\mathrm{NaCl}$ and PEG treatments were at an equal level in root (Figures 1C,D).

\section{Effects of Si on $\mathrm{Na}$ and $\mathrm{K}$ Concentrations}

After a 5-day treatment, $\mathrm{NaCl}$ caused significant $\mathrm{Na}$ accumulation and disrupted $\mathrm{Na} / \mathrm{K}$ balance in both the shoot and root, while non-ionic osmotic stress (PEG) induced no obvious effect on $\mathrm{Na}$ and $\mathrm{K}$ in rice seedling except a decline of plant total $\mathrm{K}$ accumulation content (Figure 2). Under $\mathrm{NaCl}$ treatment, the addition of Si significantly decreased shoot $\mathrm{Na}$ concentration $(P<0.05)$ but not in rice root (Figure 2A). $\mathrm{NaCl}$ treatment also decreased $\mathrm{K}$ concentration in both the shoot and root, but $\mathrm{Si}$ addition had no obvious effect on $\mathrm{K}$ concentration in either the shoot or root (Figure 2B). $\mathrm{NaCl}$ treatment raised $\mathrm{Na} / \mathrm{K}$ ratio in both the shoot and root, while $\mathrm{Si}$ addition alleviated the increment of $\mathrm{Na} / \mathrm{K}$ ratio in the shoot but not in the root (Figure 2C). In addition, exogenous $\mathrm{Si}$ increased $\mathrm{Na}$ accumulation in the root, while it decreased that in the shoot (Figure 2D). As for total $\mathrm{Na}$ and $\mathrm{K}$ accumulation content in rice seedling, $\mathrm{NaCl}$ treatment increased total $\mathrm{Na}$ content and decreased total $\mathrm{K}$ content, which was alleviated by $\mathrm{Si}$ addition (Figures 2E,F). Si also ameliorated total $\mathrm{K}$ content decline, which was induced by PEG treatment (Figure 2E). Moreover, Si decreased Na uptake rate (Figure 2F) and altered $\mathrm{Na}$ distribution between the shoot 
TABLE 1 | Shoot dry weight (DW), photosynthetic rate (Pn), transpiration rate (Tr), chlorophyll concentration, shoot malondialdehyde (MDA) concentration, shoot electrolyte leakage (EL), and shoot relative water content (RWC) of rice under different treatments. Alleviation effects of Si on these parameters in rice under NaCl or PEG treatments.

\begin{tabular}{|c|c|c|c|c|c|c|c|c|}
\hline \multirow[t]{2}{*}{ Parameter } & \multirow[t]{2}{*}{ Control } & \multirow[t]{2}{*}{$+\mathrm{Si}$} & \multirow[t]{2}{*}{$\mathrm{NaCl}$} & \multirow[t]{2}{*}{$\mathrm{NaCl}+\mathrm{Si}$} & \multirow[t]{2}{*}{ PEG } & \multirow[t]{2}{*}{$\mathrm{PEG}+\mathrm{Si}$} & \multicolumn{2}{|c|}{ Alleviation effect of $\mathrm{Si}$} \\
\hline & & & & & & & $\mathrm{NaCl}$ & PEG \\
\hline Shoot DW (mg) & $380 \pm 15 a$ & $383 \pm 22 a$ & $303 \pm 13 b$ & $370 \pm 17 a$ & $323 \pm 6 b$ & $365 \pm 11 a$ & $+17.6 \%$ & $+11.2 \%$ \\
\hline $\operatorname{Pn}\left(\mu \mathrm{mol} \mathrm{CO} 2 \mathrm{~m}^{2} \mathrm{~s}^{-1}\right)$ & $11.5 \pm 0.8 a$ & $10.9 \pm 0.3 a$ & $5.93 \pm 0.60 c$ & $8.05 \pm 0.66 b$ & $6.27 \pm 0.53 c$ & $7.90 \pm 0.33 b$ & $+18.4 \%$ & $+14.1 \%$ \\
\hline $\operatorname{Tr}\left(\mathrm{mmol} \mathrm{H} \mathrm{O}_{2} \mathrm{~m}^{-2} \mathrm{~h}^{-1}\right)$ & $2.50 \pm 0.26 a$ & $2.39 \pm 0.24 a$ & $1.11 \pm 0.19 c$ & $1.69 \pm 0.14 b$ & $1.23 \pm 0.15 c$ & $1.61 \pm 0.17 b$ & $+23.2 \%$ & $+15.2 \%$ \\
\hline Chlorophyll (mg g ${ }^{-1} \mathrm{FW}$ ) & $3.75 \pm 0.13 a b$ & $3.92 \pm 0.14 a$ & $3.03 \pm 0.08 c$ & $3.50 \pm 0.13 b$ & $3.23 \pm 0.07 c$ & $3.81 \pm 0.10 a$ & $+12.5 \%$ & $+15.5 \%$ \\
\hline MDA (nmol g $\left.\mathrm{g}^{-1} \mathrm{FW}\right)$ & $8.99 \pm 0.78 c$ & $6.28 \pm 0.32 c$ & $22.5 \pm 2.9 a$ & $11.0 \pm 1.9 c$ & $16.0 \pm 2.0 b$ & $9.84 \pm 1.45 c$ & $-127 \%$ & $-68.7 \%$ \\
\hline EL (\%) & $16.3 \pm 1.8 \mathrm{c}$ & $16.6 \pm 3.0 c$ & $54.8 \pm 3.5 a$ & $22.5 \pm 1.4 b$ & $28.2 \pm 3.2 b$ & $17.6 \pm 1.5 c$ & $-198 \%$ & $-64.8 \%$ \\
\hline RWC (\%) & $82.9 \pm 1.5 a$ & $82.7 \pm 1.2 \mathrm{a}$ & $75.2 \pm 1.5 c$ & $78.5 \pm 1.4 b$ & $76.9 \pm 1.2 \mathrm{c}$ & $80.7 \pm 0.8 a b$ & $+3.22 \%$ & $+3.88 \%$ \\
\hline
\end{tabular}

Rice seedlings were grown hydroponically with control, $100 \mathrm{mM} \mathrm{NaCl}(\mathrm{NaCl})$, and 18\% (w/v) PEG-6000 (PEG) in the absence or presence (+ Si) of $1.5 \mathrm{mM}$ Si for 5 days.

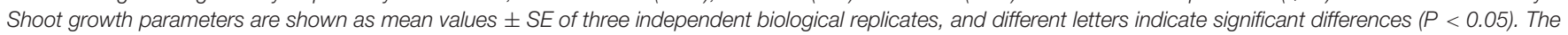
alleviation effects of Si were calculated using mean values.

TABLE 2 | Root dry weight (DW), root/shoot ratio, total root length, root surface area, root number, root malondialdehyde (MDA) concentration, root electrolyte leakage (EL), and root relative water content (RWC) of rice under different treatments. Alleviation effects of Si on these parameters in rice under NaCl or PEG treatments.

\begin{tabular}{|c|c|c|c|c|c|c|c|c|}
\hline \multirow[t]{2}{*}{ Parameter } & \multirow[t]{2}{*}{ Control } & \multirow[t]{2}{*}{$+\mathrm{Si}$} & \multirow[t]{2}{*}{$\mathrm{NaCl}$} & \multirow{2}{*}{$\mathrm{NaCl}+\mathrm{Si}$} & \multirow[t]{2}{*}{ PEG } & \multirow{2}{*}{$\mathrm{PEG}+\mathrm{Si}$} & \multicolumn{2}{|c|}{ Alleviation effect of $\mathrm{Si}$} \\
\hline & & & & & & & $\mathrm{NaCl}$ & PEG \\
\hline Root DW (mg) & $81.1 \pm 2.6 a$ & $83.4 \pm 4.1 \mathrm{a}$ & $46.1 \pm 3.6 d$ & $67.4 \pm 4.0 \mathrm{bc}$ & $63.0 \pm 3.0 c$ & $74.7 \pm 3.4 \mathrm{ab}$ & $+26.2 \%$ & $+14.5 \%$ \\
\hline Root/shoot ratio (\%) & $21.4 \pm 1.1 \mathrm{a}$ & $21.8 \pm 1.2 \mathrm{a}$ & $15.2 \pm 0.5 c$ & $18.3 \pm 2.0 b$ & $19.5 \pm 0.7 a b$ & $20.5 \pm 2.0 a b$ & $+14.4 \%$ & $+4.39 \%$ \\
\hline Total length (cm) & $401 \pm 31 a b$ & $447 \pm 57 a$ & $196 \pm 7 d$ & $312 \pm 33 c$ & $279 \pm 38 c$ & $380 \pm 18 b$ & $+31.3 \%$ & $+25.2 \%$ \\
\hline Surface area $\left(\mathrm{cm}^{2}\right)$ & $29.3 \pm 2.8 a$ & $32.0 \pm 3.7 a$ & $10.4 \pm 1.2 d$ & $16.1 \pm 0.4 c$ & $17.1 \pm 1.6 \mathrm{c}$ & $23.3 \pm 2.1 b$ & $+19.5 \%$ & $+21.2 \%$ \\
\hline Root number & $333 \pm 17 a b$ & $407 \pm 36 a$ & $176 \pm 20 d$ & $267 \pm 39 b$ & $243 \pm 16 c$ & $326 \pm 18 b$ & $+27.4 \%$ & $+25.0 \%$ \\
\hline MDA $\left(n m o l g^{-1} F W\right)$ & $7.59 \pm 0.30 c$ & $5.66 \pm 0.37 c$ & $16.9 \pm 1.9 \mathrm{a}$ & $6.68 \pm 1.29 c$ & $11.4 \pm 0.9 b$ & $6.24 \pm 0.68 c$ & $-160 \%$ & $-67.9 \%$ \\
\hline EL (\%) & $41.4 \pm 3.1 c$ & $40.2 \pm 1.3 c$ & $67.4 \pm 3.8 a$ & $57.3 \pm 3.1 b$ & $57.1 \pm 4.4 b$ & $41.6 \pm 1.2 \mathrm{c}$ & $-24.3 \%$ & $-37.7 \%$ \\
\hline RWC (\%) & $82.8 \pm 1.3 a$ & $81.7 \pm 0.9 a$ & $76.0 \pm 0.8 b$ & $81.7 \pm 2.6 a$ & $77.8 \pm 1.2 b$ & $83.5 \pm 0.9 a$ & $+5.64 \%$ & $+6.81 \%$ \\
\hline
\end{tabular}

Rice seedlings were grown hydroponically with control, $100 \mathrm{mM} \mathrm{NaCl}(\mathrm{NaCl})$, and 18\% (W/V) PEG-6000 (PEG) in the absence or presence (+ Si) of $1.5 \mathrm{mM}$ Si for 5 days.

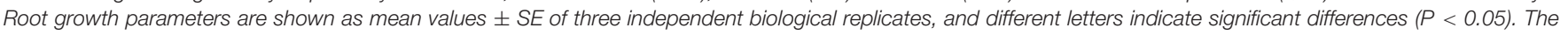
alleviation effects of Si were calculated using mean values.

and root with more $\mathrm{Na}$ sequestered in the root under $\mathrm{NaCl}$ treatment (Figure 2G).

\section{Effects of Si on Tissue Osmotic Potential and Osmolyte Concentrations}

Exogenous Si significantly increased shoot sap osmotic potential but decreased root sap osmotic potential under both $\mathrm{NaCl}$ and PEG treatments (Figure 3A). As for compatible osmolytes, both $\mathrm{NaCl}$ and $\mathrm{PEG}$ treatments increased the concentrations of soluble sugar and proline and decreased soluble protein concentration in rice shoot, and decreased soluble sugar and soluble protein in rice root (Figures 3B-D). However, proline concentration was not affected by $\mathrm{NaCl}$ but increased significantly by PEG in rice root (Figure 3C). Si addition decreased the concentration of soluble sugar in the shoot but increased that in the root (Figure 3B). In addition, proline concentration was decreased by $\mathrm{Si}$ addition in the shoot of rice under both $\mathrm{NaCl}$ and PEG treatments. However, Si addition only decreased the concentration of proline in the root under PEG treatment but not in that under $\mathrm{NaCl}$ treatment (Figure 3C). Moreover, soluble protein was improved significantly by $\mathrm{Si}$ in both the shoot and root of rice under $\mathrm{NaCl}$ and PEG treatments (Figure 3D).

\section{Effects of Si on Antioxidant Enzymes Activities}

Generally, Si addition changed the activity of antioxidant enzyme and the regulation effects of $\mathrm{Si}$ differed with stress conditions (Figure 4). Si addition increased SOD activity under $\mathrm{NaCl}$ treatment but decreased SOD activity under PEG treatment in both the shoot and root (Figure 4A). Si application enhanced CAT and POD activities in the shoot and root under both $\mathrm{NaCl}$ and PEG treatments significantly (Figures 4B,C), while APX activity was not altered by the addition of Si under both stress conditions (Figure 4D).

\section{Effects of Si on the Expression of Aquaporin Genes}

The expressions of six known members of the PIP gene family at 6 and $24 \mathrm{~h}$ after treatment were analyzed. The effects of Si on aquaporin gene expression varied among genes and stress conditions (Figure 5). In detail, after $6 \mathrm{~h}$ of treatment, $\mathrm{NaCl}$ treatment upregulated the expression of OsPIP1;2, OsPIP 2;2, and OsPIP2;4. PEG treatment upregulated the expression of OsPIP1;1, OsPIP1;2, OsPIP2;1, OsPIP2;4, and OsPIP2;6 with the exception 


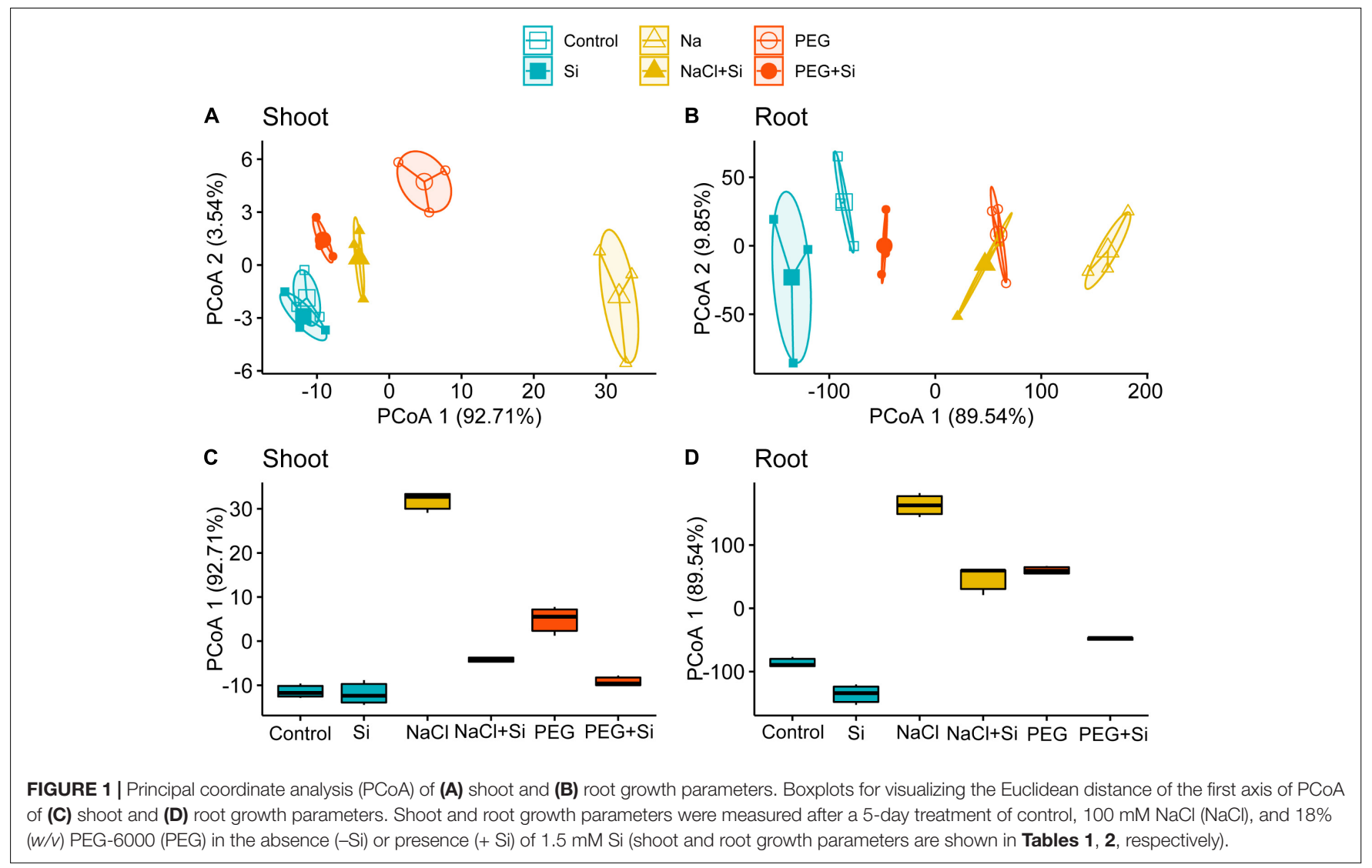

ofOsPIP2;2. Exogenous Si addition markedly downregulated the expression of these PIP genes under $\mathrm{NaCl}$ and PEG treatments. After $24 \mathrm{~h}$ of treatment, the expressions of OsPIP1;2, OsPIP2;1, and OsPIP2;2 were still increased by both $\mathrm{NaCl}$ and PEG treatments but were decreased by $\mathrm{Si}$ application. Moreover, the inhibition effect of $\mathrm{Si}$ also occurred at $24 \mathrm{~h}$ for OsPIP2;4. $\mathrm{NaCl}$ treatment reduced the expression of OsPIP2;6, while no significant effect of Si addition was observed.

\section{DISCUSSION}

Salt stress is one of the most common environmental problems. It has been estimated that over $20 \%$ arable land is subject to salinity stress (Munns and Tester, 2008; Munns and Gilliham, 2015). Rice is an important staple food crop that is sensitive to salt stress (Gong et al., 2006; Shi et al., 2013). Salt stress can cause rice growth limitation and yield decline, and severe salt stress would even result in plant death, which would threaten stable food supply globally (Zhu and Gong, 2014; Munns and Gilliham, 2015). Si is effective in improving the growth of plant under salinity, which imposes ionic toxicity and osmotic constraint on plant (Liang et al., 2007; Zhu and Gong, 2014; Coskun et al., 2016). In this study, we used isoosmotic growth substances developed from $\mathrm{NaCl}$ and $\mathrm{PEG}$ to distinguish the effects of $\mathrm{Si}$ in response to osmotic and ionic components of salinity stress. Interestingly, the comparison between the growth promotion effects of $\mathrm{Si}$ under $\mathrm{NaCl}$ and PEG shows $\mathrm{Si}$ alleviated ionic and osmotic components of salinity stress in rice differently between shoot and root. We further evaluated the role of $\mathrm{Si}$ in ionic homeostasis and water status maintenance in rice under salinity and found that $\mathrm{Si}$ can alleviate ionic toxicity and water constraint in rice in an organ-specific pattern and promote rice salinity tolerance at the whole plant level.

\section{Si Alleviated Salinity Stress in Rice in an Organ-Specific Pattern}

It is well-documented that both ionic and osmotic components can severely limit the growth of plant under salinity (Munns, 2002; Munns and Tester, 2008). Because of the additional ionic component, we observed more severe growth limitation and stress damages in rice under salinity than under iso-osmotic PEG-derived osmotic stress in this study (Tables 1, 2). In line with previous researches concerning the effects of Si under salinity or osmotic stresses in rice (Ming et al., 2012; Shi et al., 2013), exogenous Si promoted the growth of rice seedlings under both $\mathrm{NaCl}$ and iso-osmotic PEG conditions (Tables 1, 2). However, the growth promotion effects of $\mathrm{Si}$ in rice were more significant under $\mathrm{NaCl}$ treatment than under PEG treatments, indicating that $\mathrm{Si}$ can alleviate both ionic and osmotic components of salinity stress. Therefore, it is feasible to investigate the role of $\mathrm{Si}$ in alleviating ionic toxicity and osmotic constraint by comparing the effects of Si under $\mathrm{NaCl}$ and PEG treatments. 

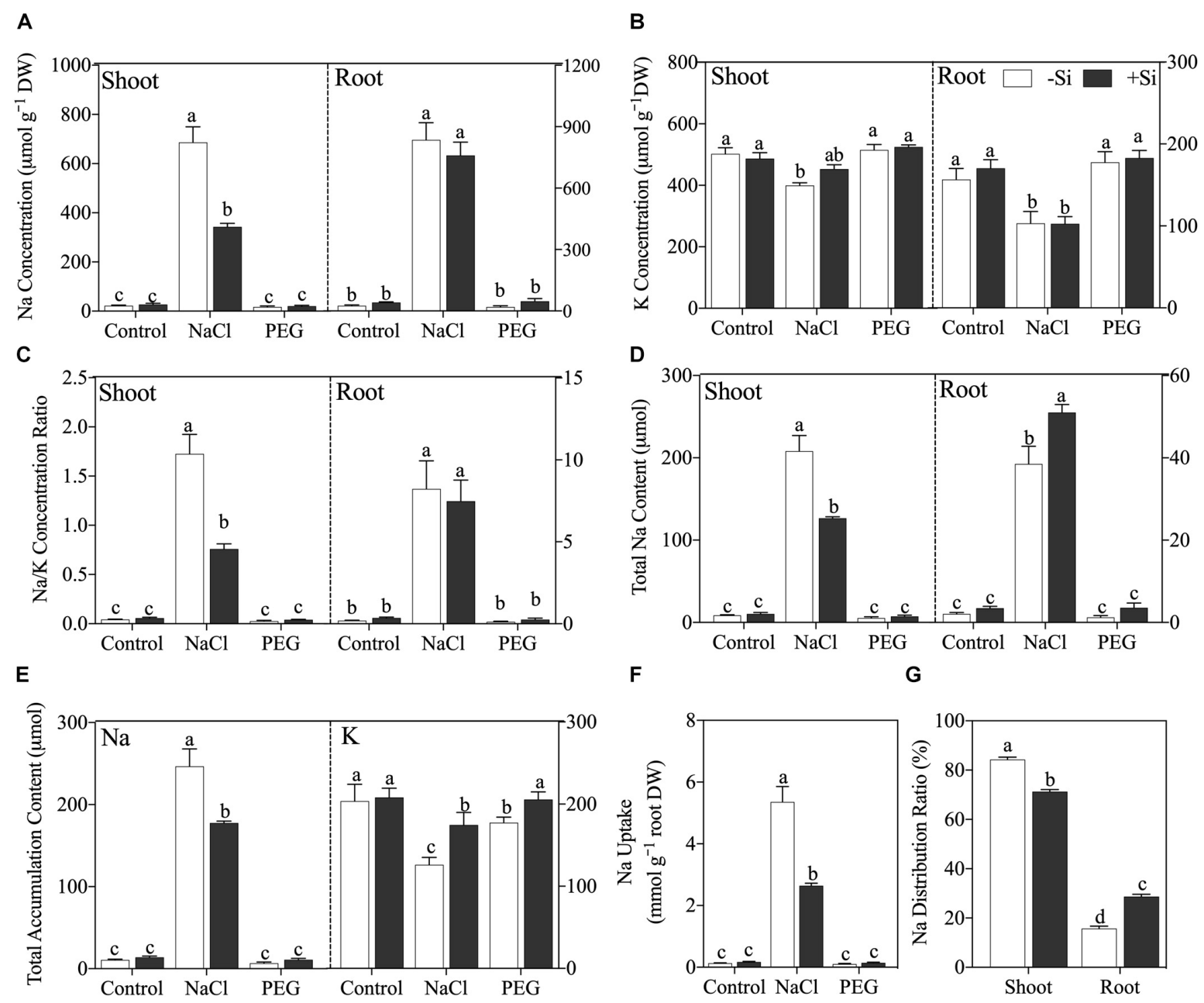

FIGURE 2 | (A) Na concentration, (B) K concentration, (C) Na/K ratio, (D) Na accumulation content in shoot and root, (E) plant total Na and K accumulation content, (F) Na uptake, and (G) Na distribution ratio. Rice were grown hydroponically with control, $100 \mathrm{mM} \mathrm{NaCl} \mathrm{(NaCl),} \mathrm{and} 18 \%$ (w/v) PEG-6000 (PEG) in the absence (-Si, white column) or presence (+ Si, black column) of $1.5 \mathrm{mM} \mathrm{Si} \mathrm{for} 5$ days. The data are the mean values $\pm \mathrm{SE}$ of three independent biological replicates, and different letters show significant differences $(P<0.05)$.

The strategy used in previous researches to distinguish the effects of ionic and osmotic components of salinity on plant metabolism (e.g., K homeostasis, polyamine metabolism, and transcription) is to subtract osmotic effect from total effects of salinity (Shabala, 2000; Lefevre et al., 2001; Umezawa et al., 2002). However, when the effect of $\mathrm{Si}$ on plant growth in response to ionic and components of salinity is assessed, it is unreliable to evaluate plant growth status using single growth parameter (e.g., DW). Therefore, we conducted PCoA to compare the effects of $\mathrm{Si}$ in rice shoot and root under $\mathrm{NaCl}$ and isoosmotic PEG with different kinds of growth parameters involved (Tables 1, 2). Consistent with the alleviation effects of $\mathrm{Si}$ in shoot and root under salt stress, the distance between control and $\mathrm{NaCl}$ treatment in PCoA was decreased by the addition of Si (Figures 1C,D). In addition, it is clearly shown in Figure $\mathbf{1}$ that $\mathrm{Si}$ could promote rice growth under salt stress through alleviating both ionic and osmotic components of salinity stress in the shoot but mainly osmotic constraint in the root. Based on the differences in growth promotion effects of Si on ionic and osmotic components between the shoot and root, it can be concluded that $\mathrm{Si}$ alleviates salt stress in an organ-specific pattern in rice.

\section{Si Alleviated Ionic Toxicity by Regulating Na Distribution}

Ionic homeostasis is essential for the plant exposed to excess Na (Munns, 2002; Munns and Tester, 2008). Under salinity, $\mathrm{Na}$ is inevitably absorbed following transpiration flow and accumulates in plant. Given the fact that $\mathrm{K}$ is closely coupled to enzyme activation and protein synthesis in plant (Wang and $\mathrm{Wu}, 2013$ ), the competition between $\mathrm{Na}$ and $\mathrm{K}$ for binding sites of transport proteins and enzymes can lead to $\mathrm{K}$ concentration decline and successive metabolism disruption in plant (Kronzucker and Britto, 2011). In this study, Si addition decreased $\mathrm{Na}$ concentration remarkably and increased 


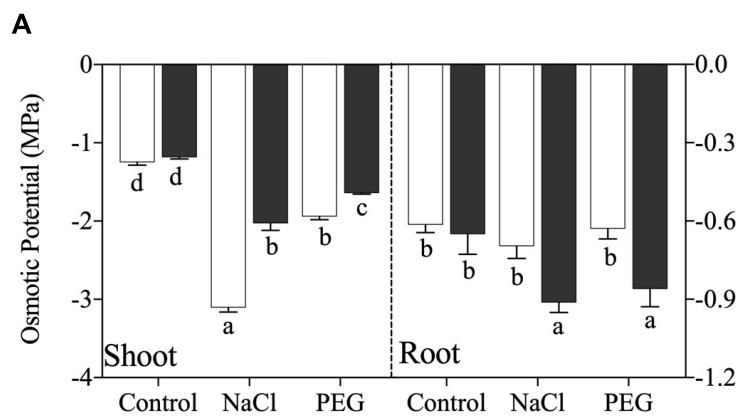

C

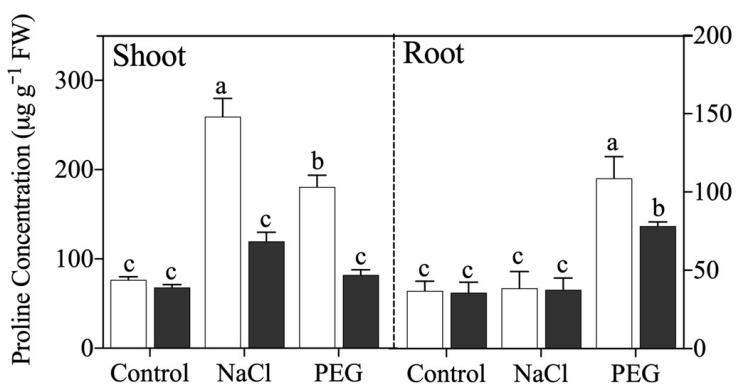

B

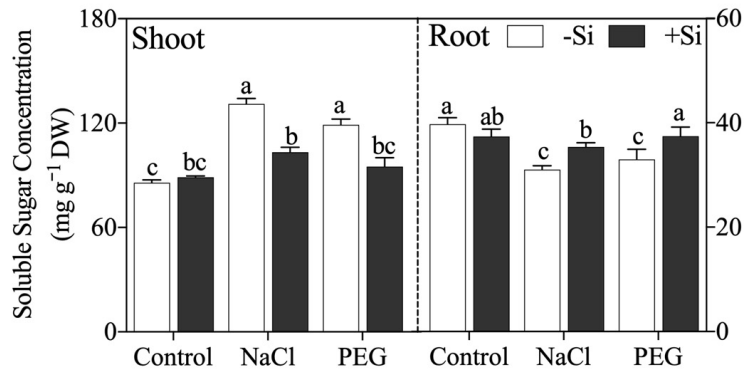

D

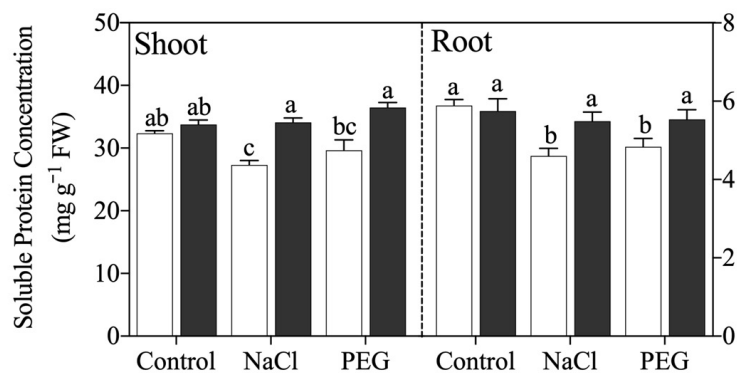

FIGURE 3 | (A) Tissue sap osmotical potential, (B) soluble sugar concentration, (C) proline concentration, and (D) soluble protein concentration in shoot and root. Rice were grown hydroponically with control, $100 \mathrm{mM} \mathrm{NaCl}(\mathrm{NaCl})$, and 18\% (w/v) PEG-6000 (PEG) in the absence (-Si, white column) or presence (+ Si, black column) of $1.5 \mathrm{mM}$ Si for 5 days. The data are the mean values \pm SE of three independent biological replicates, and different letters show significant differences $(P<0.05)$.

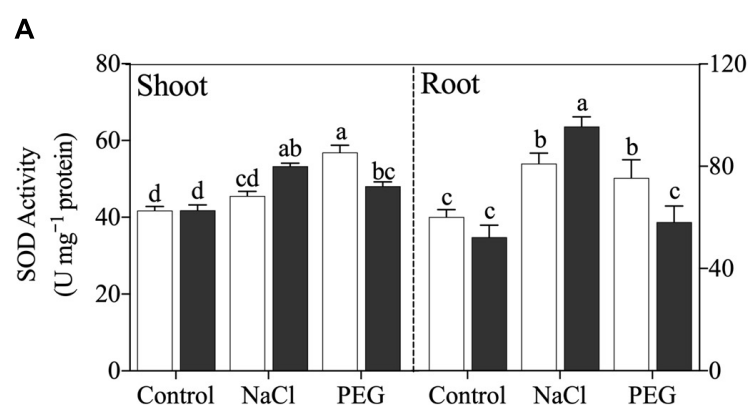

B
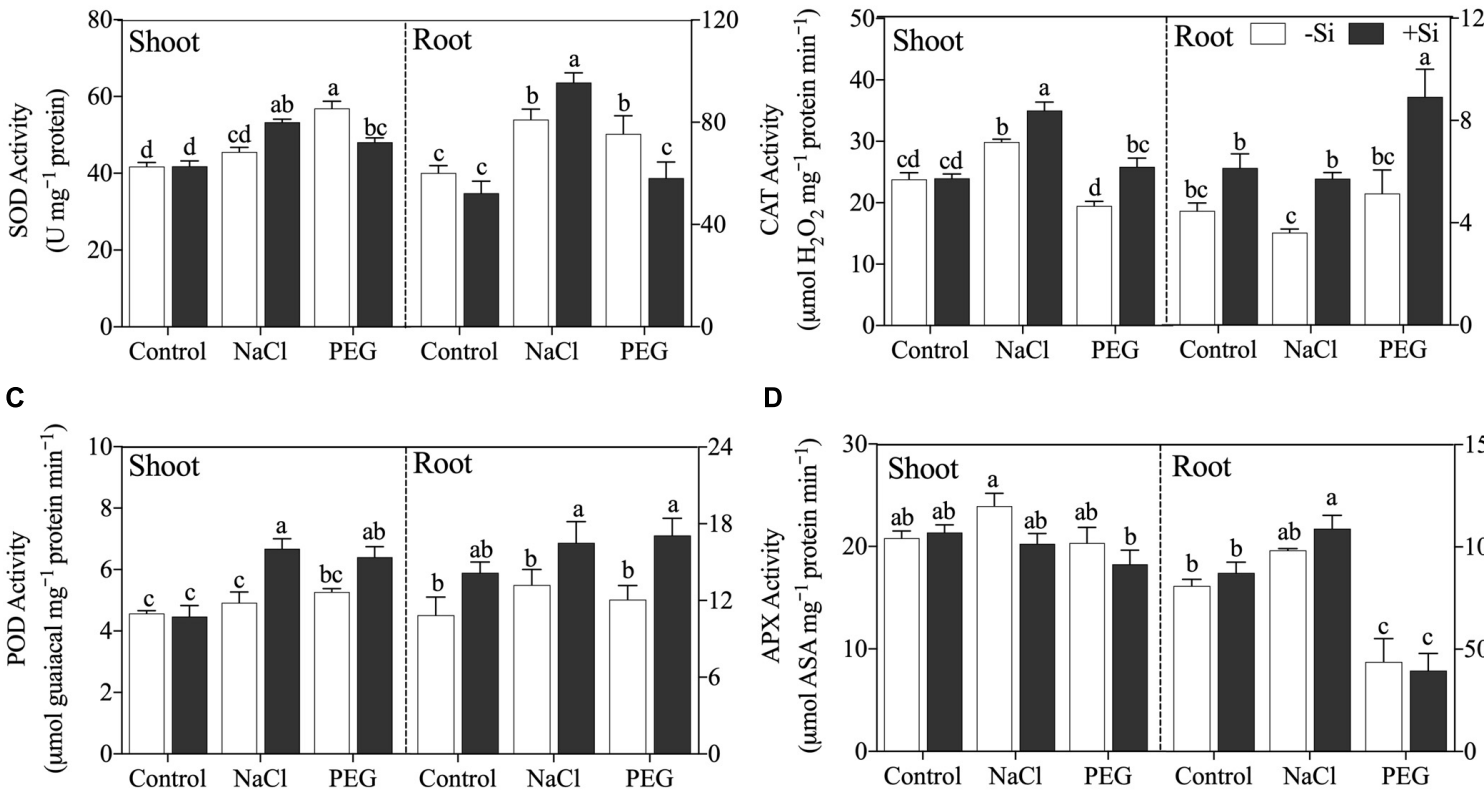

D

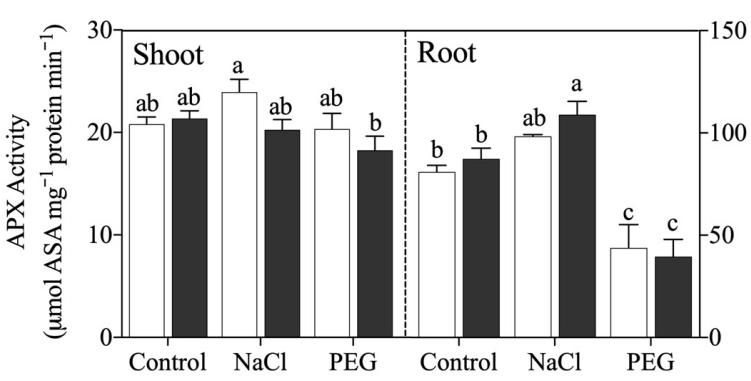

FIGURE 4 | (A) Superoxide dismutase (SOD) activity, (B) catalase (CAT) activity, (C) polyphenoloxidase (POD) activity, and (D) ascorbate peroxidase (APX) activity in shoot and root. Rice were grown hydroponically with control, $100 \mathrm{mM} \mathrm{NaCl}(\mathrm{NaCl})$, and 18\% (w/V) PEG-6000 (PEG) in the absence (-Si, white column) or presence ( $+\mathrm{Si}$, black column) of $1.5 \mathrm{mM}$ Si for 5 days. The data are the mean values \pm SE of three independent biological replicates, and different letters show significant differences $(P<0.05)$. 

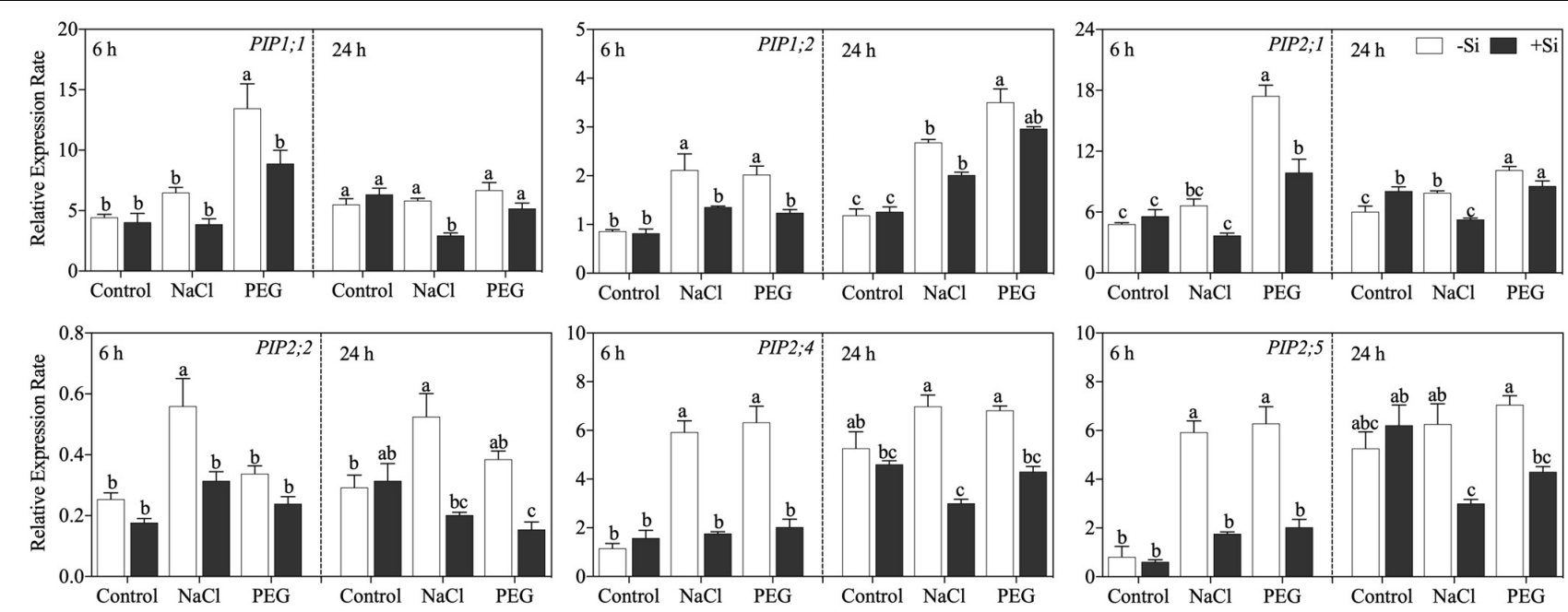

FIGURE 5 | Expression of OsPIP1;1, OsPIP1;2, OsPIP2;1, OsPIP2;2, OsPIP2;4, and OsPIP2;6 in root. Rice seedlings were pretreated with (+ Si, black column) or without (-Si, white column) $1.5 \mathrm{mM}$ Si for 3 days and then grown under control, $100 \mathrm{mM} \mathrm{NaCl}(\mathrm{NaCl})$, and $18 \%$ (w/v) PEG-6000 (PEG) for 6 or 24 h. The data are the mean values \pm SE of three independent biological replicates, and different letters show significant differences $(P<0.05)$.

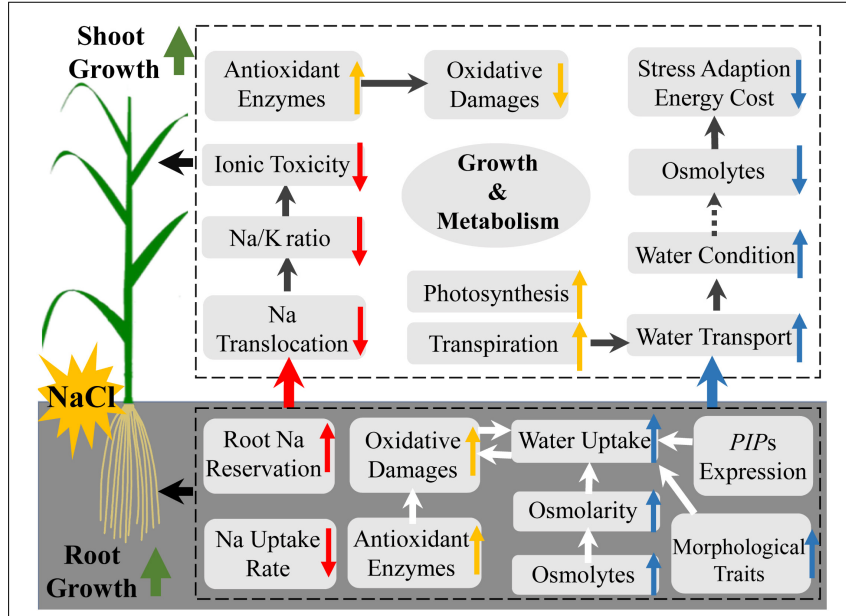

FIGURE 6 | A schematic model of the mechanisms of silicon-induced salt stress resistance in rice in relation to ionic detoxification (red arrow), water status maintenance (blue arrow), oxidative damage alleviation, and other growth regulation (yellow arrow).

K concentration (although not significantly) in rice shoot, which would protect rice from Na toxicity. However, no obvious effect of $\mathrm{Si}$ on $\mathrm{Na}$ and $\mathrm{K}$ concentrations was observed in rice root (Figure 2); this is in accordance with the result of PCoA that $\mathrm{Si}$ cannot alleviate ionic toxicity in rice root.

When subject to salinity stress, the shoot is more sensitive to $\mathrm{Na}$ than the root (Munns, 2002); therefore, it is of pivotal importance to lower shoot $\mathrm{Na}$ accumulation with respect to plant salt tolerance (Munns and Tester, 2008). Although the concentration of $\mathrm{Na}$ in rice root was not changed by $\mathrm{Si}$ addition, total $\mathrm{Na}$ accumulation content in the root was enhanced by $\mathrm{Si}$ (Figure 2) because of the $\mathrm{Si}$-induced root biomass increment (Table 2). Therefore, Si addition induced more $\mathrm{Na}$ compartmented in rice root, which can protect the shoot from Na toxicity. However, Bosnic et al. (2018) found that $\mathrm{Si}$ addition increased $\mathrm{Na}$ root-to-shoot translocation by regulating the expression of genes related to $\mathrm{Na}$ xylem loading and unloading in maize. The different effects of $\mathrm{Si}$ on $\mathrm{Na}$ translocation between rice and maize indicate the mechanism of Si-induced ionic detoxification differs with plant species. Moreover, Si decreased plant total $\mathrm{Na}$ accumulation content by decreasing net $\mathrm{Na}$ uptake rate (Figure 2), which could be due to the apoplastic blockage effect of $\mathrm{Si}$ on $\mathrm{Na}$ transport (Gong et al., 2006; Flam-Shepherd et al., 2018). In summary, our results imply that $\mathrm{Si}$ can regulate $\mathrm{Na}$ distribution between the shoot and root, thereby alleviating $\mathrm{Na}$ toxicity under salinity at the whole plant level.

\section{Si Alleviated Osmotic Constraint by Improving Water Uptake and Transport}

Maintaining optimal water status by improving root water uptake and decreasing water loss is a major strategy for plant in the adaptation to salinity stress (Steudle, 2000a,b; Aroca et al., 2012). Previous research in maize showed that Si alleviated water deficiency by reducing transpiration rate and water loss (Gao et al., 2006). By contrast, in this study, rice transpiration rate was decreased by salinity, while $\mathrm{Si}$ addition increased transpiration rate (Table 1), which would lead to more water loss. This result implies that water uptake promotion but not water loss decline could play a dominant role in Si-induced water status promotion in rice under salinity in accordance with the suggestion by Chen et al. (2018).

In plant root, water uptake capacity mainly depends on rootwater contact area, water uptake driving force, and root water permeability (Steudle, 2000a; Vandeleur et al., 2009; Sutka et al., 2011). Under water-deficit conditions (e.g., salinity stress and 
drought stress), root growth is significantly limited (Javot and Maurel, 2002; Farooq et al., 2009). In this study, Si increased total root length and total root surface area (Table 2), thereby improving root-water contact area. Besides, Si addition also decreased root sap osmotic potential (Figure 3A) through regulating the concentrations of soluble sugar and soluble protein in rice root (Figures 3B,D), thus leading to more water uptake via enhanced water uptake driving force. Moreover, it has been reported that Si can increase root water permeability through upregulating aquaporin gene expression in sorghum under water-deficit conditions (Liu et al., 2014, 2015). However, in this study, $\mathrm{NaCl}$ and PEG treatments upregulated OsPIPs expression, while $\mathrm{Si}$ decreased the expression of aquaporin genes under both $\mathrm{NaCl}$ and PEG treatments (Figure 5). Similar effects of stress condition and Si addition on the expression of PIPs have been reported in salt-stressed cucumber (Zhu et al., 2015) and drought-stressed tomato (Shi et al., 2016). These results indicate that the effects of Si on the expression of aquaporin genes differ with plant species. In rice, the upregulated expression of OsPIPs could be an adaptation strategy to disrupted water status. In this study, Si addition promoted rice water status under $\mathrm{NaCl}$ and PEG treatments by increasing root-water contact area and osmotic force; consequently, the expression of OsPIPs remained unchanged relative to control treatment.

After uptake by the root, water is transported to the shoot driven by a combination of shoot osmotic force and transpiration force. Although the Si-improved transpiration rate may lead to more water loss, it can also drive more water transport from the root to the shoot. It is worth noting that the regulation effect of Si on osmotic potential and osmolytes in rice shoot was different from that in rice root. Si increased osmotic potential and decreased the concentrations of soluble sugar and proline in rice shoot (Figure 3). Given the high energy cost in osmolytes synthesis (e.g., soluble sugar and proline), the different $\mathrm{Si}$-induced osmotic regulation strategies between the shoot and root imply that $\mathrm{Si}$ can regulate root water uptake and successively protect the shoot from excess energy cost in osmolytes metabolism (Raven, 1985). Considering the converse trends of compatible solute concentration between the shoot and the root in this study (Figure 3), we speculate that the Si-regulated osmolytes transport from the shoot to the root could be the underlying foundation of the regulation effect of $\mathrm{Si}$ on osmolytes concentrations, which is consistent with Zhu et al. (2016) who has reported that Si can increase shoot-to-root soluble sugar transport in salt-stressed cucumber. The transport of osmolytes could successively provide energy for root growth and contribute to root osmotic potential adjustment. Taken together, Si could promote root-to-shoot water transport via increasing transpiration force and root water supply.

In addition, both ionic and osmotic stresses can cause membrane oxidative damage in plant (Zhu, 2001; Munns, 2002; Tables 1, 2). Oxidative damages would disrupt the functions of plasma membrane and further influence ion balance and water uptake in plant under salinity (Zhu and Gong, 2014;
Coskun et al., 2016). In the present study, Si was effective in alleviating oxidative damages through regulating antioxidant enzymes such as SOD, CAT, POD, and APX under salinity. This is consistent with previous studies of oxidative damage in plant (Liang et al., 2003; Zhu et al., 2004). In addition, our results showed that exogenous Si could modulate these antioxidant enzymes distinctly in response to ionic and osmotic components (Figure 4). The beneficial effect of $\mathrm{Si}$ on oxidative damages contributes to ionic detoxification and water status maintenance in both the shoot and root. In the root, the Si-induced membrane stabilization can promote water uptake and regulate Na transport. However, in rice shoot, Si can maintain photosynthesis and metabolism to improve plant growth by regulating antioxidant enzymes and alleviating oxidative damages.

\section{CONCLUSION}

Our results indicate that $\mathrm{Si}$ improves salt stress tolerance in rice by alleviating ionic toxicity and osmotic constraint in an organ-specific pattern (Figure 6). Si ameliorates ionic toxicity by decreasing $\mathrm{Na}$ uptake and root-to-shoot translocation. Si alleviates osmotic constraint by regulating root morphological traits and osmotic potential but not aquaporin-related gene expression for water uptake, and promoting transpiration force but not osmotic force in the shoot for root-to-shoot water transport (Figure 6).

\section{DATA AVAILABILITY STATEMENT}

All datasets generated for this study are included in the article/Supplementary Material.

\section{AUTHOR CONTRIBUTIONS}

GY and YL designed the study and wrote the manuscript. GY, XF, $\mathrm{MP}, \mathrm{CY}$, and ZX conducted the experiment and analyzed the data.

\section{FUNDING}

This work was jointly supported by the National Natural Science Foundation of China (Approved No. 31572191) and the Fundamental Research Funds for the Central Universities (2019FZJD007).

\section{SUPPLEMENTARY MATERIAL}

The Supplementary Material for this article can be found online at: https://www.frontiersin.org/articles/10.3389/fpls.2020.00260/ full\#supplementary-material 


\section{REFERENCES}

Ahmad, M. S. A., Javed, F., and Ashraf, M. (2007). Iso-osmotic effect of $\mathrm{NaCl}$ and PEG on growth, cations and free proline accumulation in callus tissue of two indica rice (Oryza sativa L.) genotypes. Plant Growth Regul. 53, 53-63. doi: 10.1007/s10725-007-9204-9200

Almansouri, M., Kinet, J. M., and Lutts, S. (2001). Effect of salt and osmotic stresses on germination in durum wheat (Triticum durum Desf.). Plant Soil 231, 243-254. doi: 10.1023/A:1010378409663

Aroca, R., Porcel, R., and Manuel Ruiz-Lozano, J. (2012). Regulation of root water uptake under abiotic stress conditions. J. Exp. Bot. 63, 43-57. doi: 10.1093/jxb/ err266

Bates, L. S., Waldren, R. P., and Teare, I. D. (1973). Rapid determination of free proline for water-stress studies. Plant Soil 39, 205-207. doi: 10.1007/ Bf00018060

Bosnic, P., Bosnic, D., Jasnic, J., and Nikolic, M. (2018). Silicon mediates sodium transport and partitioning in maize under moderate salt stress. Environ. Exp. Bot. 155, 681-687. doi: 10.1016/j.envexpbot.2018.08.018

Bradford, M. M. (1976). Rapid and sensitive method for quantitation of microgram quantities of protein utilizing principle of protein dye binding. Anal. Biochem. 72, 248-254. doi: 10.1006/abio.1976.9999

Cakmak, I., and Marschner, H. (1992). Magnesium deficiency and high light intensity enhance activities of superoxide dismutase, ascorbate peroxidase, and glutathione reductase in bean leaves. Plant Physiol. 98, 1222-1227. doi: 10.1104/ pp.98.4.1222

Chen, D. Q., Wang, S. W., Yin, L., and Deng, X. P. (2018). How does silicon mediate plant water uptake and loss under water deficiency? Front. Plant Sci. 9:281. doi: 10.3389/fpls.2018.00281

Coskun, D., Britto, D. T., Huynh, W. Q., and Kronzucker, H. J. (2016). The role of silicon in higher plants under salinity and drought stress. Front. Plant Sci. 7:1072. doi: 10.3389/fpls.2016.01072

Epstein, E. (1994). The anomaly of silicon in plant biology. Proc. Natl. Acad. Sci. U.S.A. 91, 11-17. doi: 10.1073/pnas.91.1.11

Epstein, E. (1999). Silicon. Annu. Rev. Plant Physiol. Plant Mol. Biol. 50, 641-664. doi: 10.1146/annurev.arplant.50.1.641

Farooq, M., Wahid, A., Kobayashi, N., Fujita, D., and Basra, S. M. A. (2009). Plant drought stress: effects, mechanisms and management. Agron. Sustain. Dev. 29, 185-212. doi: 10.1051/agro:2008021

Flam-Shepherd, R., Huynh, W. Q., Coskun, D., Hamam, A. M., Britto, D. T., and Kronzucker, H. J. (2018). Membrane fluxes, bypass flows, and sodium stress in rice: the influence of silicon. J. Exp. Bot. 69, 1679-1692. doi: 10.1093/jxb/erx460

Gao, X. P., Zou, C. Q., Wang, L. J., and Zhang, F. S. (2006). Silicon decreases transpiration rate and conductance from stomata of maize plants. J. Plant Nutr. 29, 1637-1647. doi: 10.1080/01904160600851494

Giannopolitis, C. N., and Ries, S. K. (1977). Superoxide dismutases. 1. Occurrence in higher plants. Plant Physiol. 59, 309-314. doi: 10.1104/pp.59.2.309

Gong, H. J., Randall, D. P., and Flowers, T. J. (2006). Silicon deposition in the root reduces sodium uptake in rice (Oryza sativa L.) seedlings by reducing bypass flow. Plant Cell Environ. 29, 1970-1979. doi: 10.1111/j.1365-3040.2006.01572.x

Hattori, T., Sonobe, K., Inanaga, S., An, P., Tsuji, W., Araki, H., et al. (2007). Short term stomatal responses to light intensity changes and osmotic stress in sorghum seedlings raised with and without silicon. Environ. Exp. Bot. 60, 177-182. doi: 10.1016/j.envexpbot.2006.10.004

Heath, R. L., and Packer, L. (1968). Photoperoxidation in isolated chloroplasts. I. Kinetics and stoichiometry of fatty acid peroxidation. Arch. Biochem. Biophys. 125, 189-198. doi: 10.1016/0003-9861(68)90654-90651

Javot, H., and Maurel, C. (2002). The role of aquaporins in root water uptake. Ann. Bot. 90, 301-313. doi: 10.1093/aob/mcf199

Kronzucker, H. J., and Britto, D. T. (2011). Sodium transport in plants: a critical review. New Phytol. 189, 54-81. doi: 10.1111/j.1469-8137.2010.03540.x

Lefevre, I., Gratia, E., and Lutts, S. (2001). Discrimination between the ionic and osmotic components of salt stress in relation to free polyamine level in rice (Oryza sativa). Plant Sci. 161, 943-952. doi: 10.1016/S0168-9452(01)00485-X

Liang, Y. C., Chen, Q., Liu, Q., Zhang, W. H., and Ding, R. X. (2003). Exogenous silicon ( $\mathrm{Si}$ ) increases antioxidant enzyme activity and reduces lipid peroxidation in roots of salt-stressed barley (Hordeum vulgare L.). J. Plant Physiol. 160, 1157-1164. doi: 10.1078/0176-1617-1065
Liang, Y. C., Hua, H. X., Zhu, Y. G., Zhang, J., Cheng, C. M., and Römheld, V. (2006). Importance of plant species and external silicon concentration to active silicon uptake and transport. New Phytol. 172, 63-72. doi: 10.1111/j.1469-8137. 2006.01797.x

Liang, Y. C., Nikolic, M., Bélanger, R., Gong, H. J., and Song, A. L. (2015). Silicon in Agriculture: from Theory to Practice. Dordrecht: Springer.

Liang, Y. C., Si, J., and Römheld, V. (2005a). Silicon uptake and transport is an active process in Cucumis sativus. New Phytol. 167, 797-804. doi: 10.1111/j. 1469-8137.2005.01463.x

Liang, Y. C., Sun, W. C., Zhu, Y. G., and Christie, P. (2007). Mechanisms of siliconmediated alleviation of abiotic stresses in higher plants: a review. Environ. Pollut. 147, 422-428. doi: 10.1016/j.envpol.2006.06.008

Liang, Y. C., Zhang, W. H., Chen, Q., and Ding, R. X. (2005b). Effects of silicon on $\mathrm{H}+$-ATPase and H+-PPase activity, fatty acid composition and fluidity of tonoplast vesicles from roots of salt-stressed barley (Hordeum vulgare L.). Environ. Exp. Bot. 53, 29-37. doi: 10.1016/j.envexpbot.2004.02.010

Liu, P., Yin, L. N., Deng, X. P., Wang, S. W., Tanaka, K., and Zhang, S. Q. (2014). Aquaporin-mediated increase in root hydraulic conductance is involved in silicon-induced improved root water uptake under osmotic stress in Sorghum bicolor L. J. Exp. Bot. 65, 4747-4756. doi: 10.1093/jxb/eru220

Liu, P., Yin, L. N., Wang, S. W., Zhang, M. J., Deng, X. P., Zhang, S. Q., et al. (2015). Enhanced root hydraulic conductance by aquaporin regulation accounts for silicon alleviated salt-induced osmotic stress in Sorghum bicolor L. Environ. Exp. Bot. 111, 42-51. doi: 10.1016/j.envexpbot.2014.10.006

Lutts, S., Kinet, J. M., and Bouharmont, J. (1996). NaCl-induced senescence in leaves of rice (Oryza sativa L.) cultivars differing in salinity resistance. Ann. Bot. 78, 389-398. doi: 10.1006/anbo.1996.0134

Ma, J. F., and Yamaji, N. (2015). A cooperative system of silicon transport in plants. Trends Plant Sci. 20, 435-442. doi: 10.1016/j.tplants.2015.04.007

Ming, D. F., Pei, Z. F., Naeem, M. S., Gong, H. J., and Zhou, W. J. (2012). Silicon alleviates PEG-induced water-deficit stress in upland rice seedlings by enhancing osmotic adjustment. J. Agron. Crop Sci. 198, 14-26. doi: 10.1111/j. 1439-037X.2011.00486.x

Munns, R. (2002). Comparative physiology of salt and water stress. Plant Cell Environ. 25, 239-250. doi: 10.1046/j.0016-8025.2001.00808.x

Munns, R., and Gilliham, M. (2015). Salinity tolerance of crops - what is the cost? New Phytol. 208, 668-673. doi: 10.1111/nph.13519

Munns, R., and Tester, M. (2008). Mechanisms of salinity tolerance. Annu. Rev. Plant Biol. 59, 651-681. doi: 10.1146/annurev.arplant.59.032607.092911

Nakano, Y., and Asada, K. (1981). Hydrogen peroxide is scavenged by ascorbatespecific peroxidase in spinach chloroplasts. Plant Cell Physiol. 22, 867-880.

Oksanen, J., Blanchet, G., Friendly, M., Kindt, R., Legendre, P., and McGlinn, D. (2019). Vegan: Community Ecology Package. R Package Version 2.5-4.

Porra, R. J., Thompson, W. A., and Kriedemann, P. E. (1989). Determination of accurate extinction coefficients and simultaneous-equations for assaying chlorophyll-a and chlorophyll-b extracted with 4 different solvents-verification of the concentration of chlorophyll standards by atomic-absorption spectroscopy. Biochim. Biophys. Acta 975, 384-394. doi: 10.1016/S0005-2728(89)80347-80340

R Core Team (2014). A Language and Environment for Statistical Computing. Vienna: $\mathrm{R}$ foundation for statistical omputing.

Raven, J. A. (1985). Regulation of $\mathrm{pH}$ and generation of osmolarity in vascular plants - a cost-benefit analysis in relation to efficiency of use of energy, nitrogen and water. New Phytol. 101, 25-77. doi: 10.1111/j.1469-8137.1985.tb02816.x

Saqib, M., Zörb, C., and Schubert, S. (2008). Silicon-mediated improvement in the salt resistance of wheat (Triticum aestivum) results from increased sodium exclusion and resistance to oxidative stress. Funct. Plant Biol. 35, 633-639. doi: 10.1071/FP08100

Shabala, S. (2000). Ionic and osmotic components of salt stress specifically modulate net ion fluxes from bean leaf mesophyll. Plant Cell Environ. 23, 825-837. doi: 10.1046/j.1365-3040.2000.00606.x

Shi, Y., Wang, Y. C., Flowers, T. J., and Gong, H. J. (2013). Silicon decreases chloride transport in rice (Oryza sativa L.) in saline conditions. J. Plant Physiol. 170, 847-853. doi: 10.1016/j.jplph.2013.01.018

Shi, Y., Zhang, Y., Han, W. H., Feng, R., Hu, Y. H., Guo, J., et al. (2016). Silicon enhances water stress tolerance by improving root hydraulic conductance in Solanum lycopersicum L. Front. Plant Sci. 7:196. doi: 10.3389/fpls.2016.00196 
Steudle, E. (2000a). Water uptake by plant roots: an integration of views. Plant Soil 226, 45-56. doi: 10.1023/A:1026439226716

Steudle, E. (2000b). Water uptake by roots: effects of water deficit. J. Exp. Bot. 51, 1531-1542. doi: 10.1093/jexbot/51.350.1531

Sutka, M., Li, G. W., Boudet, J., Boursiac, Y., Doumas, P., and Maurel, C. (2011). Natural variation of root hydraulics in arabidopsis grown in normal and saltstressed conditions. Plant Physiol. 155, 1264-1276. doi: 10.1104/pp.110.163113

Umezawa, T., Mizuno, K., and Fujimura, T. (2002). Discrimination of genes expressed in response to the ionic or osmotic effect of salt stress in soybean with cDNA-AFLP. Plant Cell Environ. 25, 1617-1625. doi: 10.1046/j.1365-3040. 2002.00939.x

Vandeleur, R. K., Mayo, G., Shelden, M. C., Gilliham, M., Kaiser, B. N., and Tyerman, S. D. (2009). The role of plasma membrane intrinsic protein aquaporins in water transport through roots: diurnal and drought stress responses reveal different strategies between isohydric and anisohydric cultivars of grapevine. Plant Physiol. 149, 445-460. doi: 10.1104/pp.108.128645

Wakeel, A., Farooq, M., Qadir, M., and Schubert, S. (2011). Potassium substitution by sodium in plants. Crit. Rev. Plant Sci. 30, 401-413. doi: 10.1080/07352689. 2011.587728

Wang, S. W., Liu, P., Chen, D. Q., Yin, L. N., Li, H. B., and Deng, X. P. (2015). Silicon enhanced salt tolerance by improving the root water uptake and decreasing the ion toxicity in cucumber. Front. Plant Sci. 6:759. doi: 10.3389/ fpls.2015.00759

Wang, Y., and Wu, W. H. (2013). Potassium Transport and Signaling in Higher Plants. Annu. Rev. Plant Biol. 64, 451-476. doi: 10.1146/annurev-arplant050312-120153

Weatherley, P. E. (1950). Studies in the water relations of the cotton plant. 1. The field measurement of water deficits in leaves. New Phytol. 49, 81-97. doi: 10.1111/j.1469-8137.1950.tb05146.x

Yan, G. C., Nikolic, M., Ye, M. J., Xiao, Z. X., and Liang, Y. C. (2018). Silicon acquisition and accumulation in plant and its significance for agriculture. J. Interg. Agric. 17, 2138-2150. doi: 10.1016/S2095-3119(18)62037-62034
Yin, L. N., Wang, S. W., Tanaka, K., Fujihara, S., Itai, A., Den, X. P., et al. (2016). Silicon-mediated changes in polyamines participate in silicon-induced salt tolerance in Sorghum bicolor L. Plant Cell Environ. 39, 245-258. doi: 10. $1111 /$ pce. 12521

Zhu, J. K. (2001). Plant salt tolerance. Trends Plant Sci. 6, 66-71. doi: 10.1016/ S1360-1385(00)01838-1830

Zhu, Y. X., and Gong, H. J. (2014). Beneficial effects of silicon on salt and drought tolerance in plants. Agron. Sustain. Dev. 34, 455-472. doi: 10.1007/s13593-0130194- 191

Zhu, Y. X., Guo, J., Feng, R., Jia, J. H., Han, W. H., and Gong, H. J. (2016). The regulatory role of silicon on carbohydrate metabolism in Cucumis sativus L. under salt stress. Plant Soil 406, 231-249. doi: 10.1007/s11104-016-28772872

Zhu, Y. X., Xu, X. B., Hu, Y. H., Han, W. H., Yin, J. L., Li, H. L., et al. (2015). Silicon improves salt tolerance by increasing root water uptake in Cucumis sativus L. Plant Cell Rep. 34, 1629-1646. doi: 10.1007/s00299-015-18141819

Zhu, Z. J., Wei, G. Q., Li, J., Qian, Q. Q., and Yu, J. Q. (2004). Silicon alleviates salt stress and increases antioxidant enzymes activity in leaves of salt-stressed cucumber (Cucumis sativus L.). Plant Sci. 167, 527-533. doi: 10.1016/j.plantsci. 2004.04.020

Conflict of Interest: The authors declare that the research was conducted in the absence of any commercial or financial relationships that could be construed as a potential conflict of interest.

Copyright (c) 2020 Yan, Fan, Peng, Yin, Xiao and Liang. This is an open-access article distributed under the terms of the Creative Commons Attribution License (CC BY). The use, distribution or reproduction in other forums is permitted, provided the original author(s) and the copyright owner(s) are credited and that the original publication in this journal is cited, in accordance with accepted academic practice. No use, distribution or reproduction is permitted which does not comply with these terms. 